\title{
CICLO DE APRENDIZAGEM E A PRODUÇÃO DE NOTÍCIAS JORNALÍSTICAS EM UM CONTEXTO ESCOLAR
}

Carolina Zeferino Pires*

RESUMO: Este artigo fundamenta-se teoricamente à Linguística Sistêmico-funcional de Halliday (2014) e à Pedagogia de Gêneros (Martin; Rose, 2008, 2012) e tem como objetivo apresentar a implementação do Ciclo de Aprendizagem com alunos do sexto ano do Ensino Fundamental em uma escola da rede pública. Buscou-se, dessa forma, evidenciar possíveis formas de aprendizagem explícita do gênero notícias, bem como a escrita autônoma de textos. A metodologia aplicada é estabelecida pelo Ciclo de Aprendizagem com alunos que frequentam o turno inverso para um projeto de letramento, oferecido por uma professora da rede municipal. Apresenta-se a análise da produção de um aluno e discute-se a influência da implementação do Ciclo no letramento dos alunos envolvidos.

PALAVRAS-CHAVE: Ciclo de aprendizagem; Gênero; Linguística sistêmico-funcional; Pedagogia de gêneros.

\section{Introdução}

O objetivo deste artigo é apresentar a implementação de uma proposta de ensino de leitura e de escrita com base no Ciclo de Aprendizagem de Martin e Rose (2008) para alunos do sexto ano do ensino fundamental de uma escola da rede pública de Porto Alegre. As bases teóricas que nortearam a sua implementação, a saber, a linguística sistêmico-funcional (LSF) proposta por Halliday (2014), a noção de gênero e a metodologia conhecida como Pedagogia de Gêneros cuja aplicação prática dá-se através do Ciclo de Aprendizagem, propostos por Martin e Rose (2012). Além da LSF, a Pedagogia de gêneros foi influenciada pela sociologia de Bernstein $(1990 ; 2000)$ e pela concepção interacionista de Painter (1984).

A Pedagogia de Gêneros pressupõe que os alunos sejam guiados e preparados pelos professores antes que eles consigam ler e escrever independentemente. As intervenções orais oriundas do professor e as escritas conjuntas são formas de guiar o aluno por esse

* Professora do Instituto Federal Farroupilha (IFFar). Mestre em Letras pela Universidade Federal do Rio Grande do Sul, Brasil (UFRGS). 
processo de aprendizagem da língua. Reconhece-se, então, a necessidade de (re)pensar novas formas e metodologias para serem desenvolvidas nas aulas de língua materna na rede pública brasileira.

Assim, este artigo desdobra-se em três partes, uma teórica, sobre a Pedagogia de Gêneros e o Ciclo de Aprendizagem e outra prática, sobre a sua implementação e, por fim, as Considerações finais.

\section{Linguística Sistêmico-funcional e Pedagogia de Gêneros}

De acordo com Eggins (2014), a língua é funcional porque a sua função é criar significados, que são influenciados pelo contexto social e cultural em que o falante está exposto. E é sistêmica por constituir-se como um sistema semiótico disponível aos falantes. Trata-se, portanto, de uma teoria tanto sistêmica quanto funcional da linguagem.

Ancorada pela LSF, a Pedagogia de Gêneros foi designada Martin e Rose (2012) a partir de pesquisas acerca dos textos usados nas escolas australianas. Para tanto, conceituaram gênero como "processo social organizado em etapas e orientado por propósitos sociais” (MARTIN; ROSE, 2012, p.1: tradução nossa). Segundo os autores, os gêneros são sociais porque são realizados coletivamente e o escritor ou falante os configuram de acordo com o tipo de leitor; compõem-se por estágios porque é preciso mais de uma etapa para concluí-los e são orientados por objetivos porque são utilizados com algum propósito.

O estudo de gêneros tinha como objetivo principal melhorar o letramento dos alunos. A partir desta proposta, os autores desenvolveram uma metodologia que abrangesse a sua teoria em prática pedagógica. As estratégias de ensino propostas pelos autores ficaram conhecidas como Pedagogia de Gêneros, projetada para que o aluno seja capaz de, por meio da leitura crítica de textos, controlar o gênero através da prática guiada de leitura. (ROSE, 2015a). Metodologicamente, a Pedagogia assume dois princípios fundamentais: primeiro, a leitura é a impulsionadora da aprendizagem e, segundo, o problema central da educação está relacionado aos desiguais níveis de leitura nos quais os alunos encontram-se (ROSE, 2015a). Assim, baseados na teoria hallidyana, os autores estabelecem um modelo estratificado de linguagem em que o texto se realiza a partir do contexto de situação e de 
cultura em que está inserido, visto que estabelecem a "cultura como um sistema de gêneros". Assim,

Martin vai além de estratificar o contexto em dois níveis [contexto de situação e contexto de cultura], com o gênero especificando as combinações particulares de campo, relação e modo permitidos por uma determinada cultura, realizado por etapas e fases pelas quais um texto se desdobra. (ROSE, 2015c, p. 2: tradução nossa)

Adiciona-se ao contexto de situação e ao de cultura, o conceito de discurso pedagógico e as relações estabelecidas a partir da troca de conhecimento entre alunos e professores e entre alunos (BERNSTEIN, 2000). A crítica estabelecida por Bernstein é que o conhecimento circulante no ambiente escolar não é acessado por todos os estudantes de forma igualitária, visto não ser explícito. A escola é, então, reflexo de uma sociedade que reproduz e legitima as desigualdades entre os aprendizes que não conseguem ser bem-sucedidos no ambiente escolar.

Dessa forma, a Pedagogia de Gêneros estabelece o estudo de texto-em-contexto (ROSE, 2015c: tradução nossa) a partir do conhecimento acerca dos gêneros e, fundamentada em Bernstein, que o ensino ocorra de forma explícita. Assim, os alunos seriam capazes de dominar não somente o gênero, mas a metalinguagem envolvida e compartilhada por todos no currículo escolar. Consequentemente, metalinguagem estabelecida e utilizada em cada gênero deve ser estudada pelos alunos, de forma que eles, ao final do ensino fundamental, tenham aprendido não somente a escrita de narrativas, como também possam generalizar as experiências em textos técnicos, envolver o leitor ao usar dispositivos literários, negociar e avaliar posições em argumentações (ROSE, 2014).

Por fim, Martin (2000) buscou em Halliday (1975) e Painter (1984) os princípios de “orientação mediante interação em contexto de experiências compartilhadas” (MARTIN, 2000, p. 50: tradução nossa). O autor estabeleceu os princípios sobre os quais a aprendizagem de língua materna ocorre pela experiência compartilhada entre pais e filhos no ambiente familiar, adaptados por Rothery (1996) para a aprendizagem da escrita em ambiente 
escolar. Rothery desenvolveu, baseada nos pressupostos concebidos por Halliday, Bernstein e Painter, o Ciclo de Ensino e Aprendizagem que estabelece metodologicamente como o ensino de gêneros deve ser abordado em sala de aula.

\section{Ciclo de aprendizagem}

O Ciclo de Aprendizagem proposto por Martin e Rose (2008) segue um modelo de letramento integrado, ou seja, utiliza a leitura e a interação aluno-professor no intuito de melhorar a aprendizagem e a escrita em todas as disciplinas do currículo. O Ciclo está organizado em três níveis que contemplam distintas estratégias, conforme Figura 1.

Figura 1: níveis de estratégias do Ciclo de aprendizagem

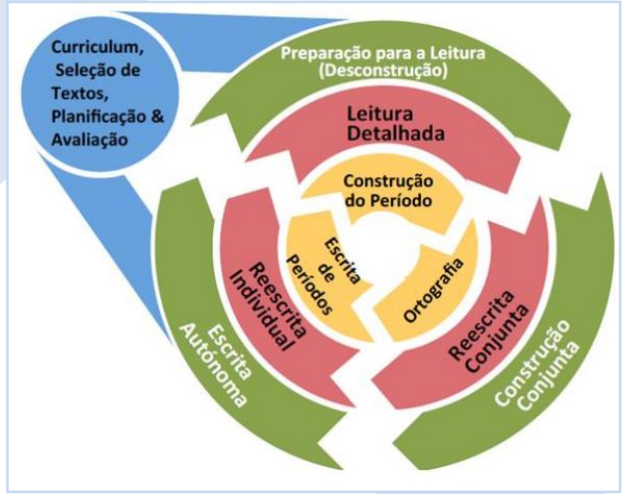

Fonte: adaptada por Gouveia (2015, p. 218).

O nível 1, mais externo, que compreende as estratégias de preparação para a leitura, construção conjunta e escrita autônoma, são etapas de aplicação que envolve o texto na sua totalidade. O nível 2 , intermediário, apresenta as etapas de leitura detalhada, reescrita conjunta e reescrita individual e são voltadas para a aprendizagem de fragmentos menores de texto, mas que evidenciam características textuais e linguísticas relevantes ao estudo desenvolvido. O nível 3, mais interno, compreende as etapas de construção de 
períodos, ortografia e escrita de períodos ${ }^{1}$. Os níveis não devem ser vistos como sequenciais, mas como níveis de suporte: os mais externos requerem menos suporte, enquanto os mais internos preveem um auxílio mais efetivo do professor.

O Ciclo de Aprendizagem começa pelo planejamento do currículo, pela seleção adequada de textos para a faixa etária dos alunos e pelo planejamento dos métodos avaliativos. A seleção de textos inicia-se a partir das discussões acerca do assunto a ser tratado em aula, do conhecimento e do interesse dos alunos. A primeira estratégia do nível 1 é a preparação para a leitura ou desconstrução do gênero, momento em que o professor explana oralmente algumas características importantes do texto e os alunos realizam consultas acerca do tópico abordado, principalmente na rede mundial de computadores, ampliando o seu repertório e preparando-os para a leitura. $\mathrm{Na}$ desconstrução, deve-se considerar o objetivo sócio comunicativo do texto, verificando a sua estrutura esquemática e características. O texto deve ser analisado conjuntamente e cada aluno, com as suas cópias, identifica e marca as etapas do gênero.

A leitura detalhada compreende a análise do texto a partir de fraseados importantes na construção de significados do gênero. Neste momento, aborda-se a sequência texto, além de acessar conhecimento do campo sobre o qual o texto se desdobra. O leitor é guiado a reconhecer os estágios do texto, ler as figuras, se houver. Ao interagir sobre a leitura, espera-se que o aluno consiga acessar os significados do texto. O texto é, neste momento, acessado em sua totalidade e prepara o aluno para o próximo nível, construção conjunta. Caso o professor escolha trabalhar com uma narrativa, deve aparecer as etapas de orientação ^ complicação ^ avaliação ^ resolução. Neste sentido, Martin e Rose (2012) ressaltam a importância de descrever a narrativa brevemente antes de iniciar a leitura, para envolver os alunos na atividade. De acordo com Gouveia:

A leitura detalhada é uma estratégia pedagógica que garante aos alunos meios de compreensão leitora, para além da normal decodifica- 
ção e interpretação de significados textuais; garante, também domínio linguístico ao fazer depender de fraseados particulares, enquanto modos de dizer/escrever, modos de significar, isto é, ao fazer depender a compreensão de fragmentos textuais da decodificação das estruturas léxico-gramaticais particulares que atuam nesses fragmentos. (GOUVEIA, 2014, p. 223)

A leitura detalhada é a estratégia em que o professor trabalha com passagens do texto guia o aluno para identificar as sentenças mais importantes do ponto de vista do desenvolvimento do gênero. Assim, o professor escolhe uma passagem de um texto para ser analisada com mais detalhes, que segue a sequência de interação com a preparação, foco, identificação, afirmação e elaboração. O professor deve ler uma passagem do texto e os alunos apresentam o seu conhecimento no foco da elaboração; o professor, então, elabora um novo conhecimento com o aluno, que pode ser o significado de uma palavra, uma característica de um personagem, uma sentença que o aluno não compreenderia sem o suporte de outra pessoa. De acordo com Rose,

O professor pode então dar a elaboração, ou solicitar aos alunos para propor uma de seu conhecimento (Quem pode contar o comeşo dos contos de fada de outra maneira? Quem se lembra o que significa viúva?) A elaboração final desta frase reforça e amplia o conhecimento explícito sobre o gênero (cenário da estória) (ROSE, 2015a, p. 18, grifos no original; tradução nossa)

Martin e Rose (2012) esclarecem que esta prática reduz a carga semiótica dos processos de aquisição do código escrito, ao possibilitar que o aluno compreenda a complexidade dos significados abordados. Um exemplo de leitura detalhada consta no Quadro 1, conforme os pressupostos desenvolvidos por Rose (2015a). 
Quadro 1: proposta de escrita detalhada com padrões de interação professor-aluno

\begin{tabular}{|c|c|c|c|c|}
\hline & Participantes & Ciclos & Fonte & Conhecimento \\
\hline $\begin{array}{l}\text { P: Este é o cenário da estória. A pri- } \\
\text { meira sentença diz que Jack vivia } \\
\text { com a mãe. Acompanhem a leitura } \\
\text { "Há muito tempo atrás em uma } \\
\text { terra muito distante vivia uma viúva } \\
\text { e o seu filho Jack." }\end{array}$ & Turma & $\begin{array}{l}\text { Prepara a } \\
\text { sentença }\end{array}$ & $\begin{array}{l}\text { Referência ao } \\
\quad \text { texto } \\
\text { Referência ao } \\
\text { texto escrito }\end{array}$ & $\begin{array}{l}\text { Cenário, pri- } \\
\text { meira sentença, } \\
\text { Jack, sua mãe. }\end{array}$ \\
\hline $\begin{array}{l}\text { P: Agora, bem no começo da sentença } \\
\text { diz. quando a estória aconteceu. } \\
\text { A, qual palavra indica quando a his- } \\
\text { tória ocorreu? }\end{array}$ & $\begin{array}{l}\text { Turma } \\
\text { Aluno } 1\end{array}$ & $\begin{array}{c}\text { Preparação } \\
\text { Foco }\end{array}$ & $\begin{array}{l}\text { Referência ao } \\
\text { texto } \\
\text { Referência ao } \\
\text { texto }\end{array}$ & $\begin{array}{l}\text { Quando aconte- } \\
\text { ceu } \\
\text { Quando }\end{array}$ \\
\hline A: Há muito tempo atrás. & Aluno 1 & Identifica & $\begin{array}{l}\text { Referência ao } \\
\text { texto escrito }\end{array}$ & Instancia \\
\hline $\begin{array}{l}\text { P: Exatamente. } \\
\text { Vamos marcar "bá muito tempo } \\
\text { atrás." }\end{array}$ & $\begin{array}{l}\text { Aluno } 1 \\
\text { Turma } \\
\end{array}$ & $\begin{array}{c}\text { Afirma } \\
\text { Direciona }\end{array}$ & $\begin{array}{l}\text { Referência ao } \\
\text { texto escrito }\end{array}$ & Repetição \\
\hline $\begin{array}{l}\text { Há muito tempo atrás significa que } \\
\text { isso aconteceu muito tempo antes de } \\
\text { vocês, seus pais ou mesmo seus avós } \\
\text { terem nascido. } \\
\text { Contos de fadas normalmente ini- } \\
\text { ciam assim. }\end{array}$ & Turma & Elaboração & $\begin{array}{l}\text { Conhecimento } \\
\text { do professor }\end{array}$ & $\begin{array}{l}\text { Definição de } \\
\text { função no gê- } \\
\text { nero }\end{array}$ \\
\hline $\begin{array}{l}\text { P: Alguém sabe outra forma de co- } \\
\text { meçar um conto de fadas para indicar } \\
\text { que algo aconteceu há muito tempo? }\end{array}$ & Turma & Foco & $\begin{array}{l}\text { Conhecimento } \\
\text { do aluno }\end{array}$ & $\begin{array}{l}\text { Quando aconte- } \\
\text { ceu }\end{array}$ \\
\hline A: Era uma vez: & Aluno 2 & Identifica & $\begin{array}{l}\text { Conhecimento } \\
\text { do aluno }\end{array}$ & \\
\hline P: Exatamente. & Aluno 2 & Afirma & & \\
\hline $\begin{array}{l}\text { Era uma vez indica que aconteceu há } \\
\text { muito tempo atrás. }\end{array}$ & Turma & Elabora & $\begin{array}{l}\text { Conhecimento } \\
\text { do professor }\end{array}$ & Repetição \\
\hline
\end{tabular}

Fonte: adaptado a partir de Rose (2015a, p. 17).

A próxima estratégia do Ciclo é conhecida como reescrita conjunta e consiste em reescrever, coletivamente, a passagem desconstruída na leitura detalhada, usando os recursos e padrões linguísticos estudados. De acordo com Rose (2015a), os textos factuais, por exemplo, são assim classificados por apresentar padrões avaliativos, enquanto as estórias utilizam-se de recursos linguísticos literários específicos. Uma sugestão apresentada pelo autor é mudar o campo da narrativa, usando os mesmos recursos e padrões do texto-base, para que o aluno tenha um ponto de partida. Os alunos, então, criam, conjuntamente, um novo evento, um novo cenário e personagens que se encaixem na nova narrativa. Dessa forma, 
Na etapa de tarefa, os alunos, então, se revezam para escrever o novo texto, assim o professor orienta a classe para propor novos elementos para cada frase. Por exemplo, como Jack in the Beanstalk é um conto de fadas, seus padrões discursivos poderiam ser apropriados para escrever uma estória diferente no mesmo registro. (ROSE, 2015a, p. 20: tradução nossa)

Ao longo da reescrita conjunta, os alunos revezam-se para escrever o novo texto no quadro ou computador com projeção e, com o auxílio do professor, discutem como será escrito. Neste momento, espera-se que os alunos se envolvam com a tarefa da escrita e retomem a passagem original sempre que necessário, para entender como os padrões de discurso funcionam no gênero escolhido. A estratégia de reescrita conjunta auxilia a produção do aluno, visto que oferece opções de escrita, evitando a ansiedade da "folha vazia sem ideias".

A reescrita individual abrange todos os passos da reescrita conjunta, mas se trata de uma tarefa em que o aluno reescreve sua própria versão. É a oportunidade para o aluno escolher o cenário, o enredo, os personagens, se ele estiver escrevendo uma narrativa, e pode usar os padrões linguísticos já estudados. Caso os alunos não estejam preparados para a reescrita individual, o professor pode considerar uma nova escrita conjunta com a participação de todos os alunos ou em pequenos grupos. As reescritas, individual ou coletiva, são atividades que envolvem passagens de textos selecionadas pelo professor.

A estratégia subsequente, construção conjunta, consiste em elaborar um novo texto coletivamente com o auxílio do professor, que deve guiar o processo de elaboração que mantenha as características do gênero, mas apresente um novo campo. O professor registra no quadro as ideias provenientes dos alunos, com um novo campo, ou seja, com novos personagens, novo cenário e enredo, caso os alunos estejam escrevendo uma estória. Todas as escolhas devem ser feitas pelo coletivo de alunos, sendo um aluno designado a escrever no quadro enquanto o professor auxilia no processo. Assim, “os alunos são orientados a aprofundar os recursos de padrões de texto específicos de autores bem-sucedidos, bem como os padrões globais do gênero” (ROSE, 2015a, p. 7: tradução nossa).

A escrita autônoma deve seguir a mesma lógica da escrita conjunta; os alunos, no entanto, escrevem o texto de forma individual. Neste momento, os estudantes já leram pelo 
menos dois textos com a mesma estrutura textual: o inicial, lido na fase de preparação para a leitura e, do mesmo modo, o escrito coletivamente por toda a turma. As ideias lançadas pelos alunos conjuntamente podem ser usadas nas escritas individuais, de forma a criar um novo campo.

O terceiro nível, que compreende as estratégias de construção de períodos, escrita de períodos e ortografia, e caracteriza-se pelo estudo pontual de padrões de escrita de palavras e de períodos, que devem ser contextualizadas a partir dos textos lidos na leitura detalhada. A construção de períodos tipifica-se pela manipulação das sentenças provenientes da leitura detalhada que devem ser colocadas em ordem. Esta atividade é realizada em grupos ou individualmente, e os alunos recebem cartões que podem construir várias sentenças. As palavras manipuladas nesta etapa servem para a atividade de ortografia, quando os alunos são requisitados a escrevê-las quando solicitados pelo professor. Os termos selecionados para a atividade de ortografia são utilizadas para a escrita de perío$\operatorname{dos}^{2}$.

$\mathrm{Na}$ implementação descrita neste artigo, a seleção de textos ocorreu por sugestão dos alunos, que gostariam de ler narrativas de terror, mais especificamente lendas urbanas. As fases do Ciclo de aprendizagem preparação para a leitura, construção conjunta, escrita autônoma, leitura detalhada, reescrita conjunta e reescrita individual foram desenvolvidas no decorrer das aulas. A aplicação da leitura detalhada não visou somente à leitura de textos que seriam posteriormente escritos pelos alunos, como também aqueles em que os alunos apresentaram mais dificuldades no momento da investigação sobre lendas urbanas.

\footnotetext{
${ }^{2}$ Ainda que apresente etapas que se desdobram de forma sequencial, o Ciclo de Aprendizagem pode ser seguir diferentes encadeamentos a partir das necessidades individuais de cada grupo de alunos. O professor pode alternar o trabalho entre as sentenças, o texto em sua totalidade ou as suas passagens. Da mesma forma, é possível combinar etapas distintas do Ciclo, visto que abre a possibilidade de ser usado parcialmente, a partir da análise do professor.
} 


\section{Implementação do Ciclo de aprendizagem em contexto escolar}

O planejamento e a implementação do projeto de letramento descrito neste artigo seguiram a metodologia proposta pela Pedagogia de Gêneros a partir do modelo integrado de leitura e de escrita e de interação aluno-professor. O planejamento envolveu um desencadeamento de atividades que possibilitasse a reflexão dos aprendizes com relação à língua em uso, tanto escrita quanto oral.

O projeto ${ }^{3}$ de letramento foi desenvolvido em uma escola municipal da rede de ensino de Porto Alegre e ofertada aos alunos do sexto anos do Ensino Fundamental. A professora encaminhou o projeto, desenvolvido em parceria com a pesquisadora, tendo como base teórico-metodológica a Pedagogia de Gêneros. Os alunos envolvidos frequentam uma das escolas da rede municipal de ensino de Porto Alegre em que a meta mínima do Ideb do quinto ano não foi alcançada nos anos de 2011 e de 2013, sendo que 50,6\% destes alunos encontram-se até o nível 2 na escala de proficiência ${ }^{4}$ com relação à leitura. Isso significa que mais da metade dos alunos consegue somente localizar informações explícitas, personagem e assunto principais e a finalidade de alguns gêneros. Os estudantes atendidos pela instituição são oriundos dos bairros periféricos à escola, e de classes menos favorecidas social e economicamente.

Após alguns encontros com a pesquisadora, a professora relatou que havia realizado algumas conversas com os alunos acerca dos textos que os alunos gostariam de ler, e muitos tinham interesse por narrativas de terror. Decidiu-se, assim, abordar a temática de lendas urbanas. A primeira ação na escola, envolvendo a temática, foi espalhar cartazes pelos corredores com a pergunta "Você sabe o que são lendas urbanas?". Esta ação tinha como objetivo engajar os alunos em uma atividade que envolvia pesquisas no ambiente virtual, da mesma forma que divulgou a ocorrência do projeto em si.

\footnotetext{
3 O projeto resultou de uma demanda da escola que, ao final do ano de 2015 , requisitou que os professores de Português da escola apresentassem projetos para atender a demanda de alunos no turno inverso ao da aula.

${ }^{4}$ Conforme descrito no site do Instituto Nacional de Estudos e Pesquisas Educacionais Anísio Teixeira - INEP, "em Língua Portuguesa (com foco em leitura) são avaliadas habilidades e competências definidas em unidades chamadas descritores, agrupadas em tópicos que compõem a Matriz de Referência dessa disciplina. (Disponível em http:/ / provabrasil.inep.gov.br/web/guest/educacao-basica/saeb/resultados. Acesso em $11 \mathrm{de}$ abril de 2017). 
Divididos em pequenos grupos, os alunos realizaram as pesquisas no ambiente virtual acerca do assunto e escolheram um texto sobre lendas, disponível na web para ser impresso e afixado pelos murais da escola, logo abaixo da pergunta ("Você sabe o que são lendas urbanas?" $)$, ação que tinha como objetivo compartilhar com os demais alunos da escola o objetivo sócio comunicativo do texto. Para tanto, iniciou-se a preparação para a leitura, de forma que os alunos ampliaram o seu repertório acerca do tema e abordaram as características principais dos textos lidos. A preparação para leitura ou desconstrução do gênero consistiu em discussões acerca do texto lido e, assim como previsto por Martin e Rose (2012, p. 148: tradução nossa), a preparação para a leitura "começa no nível interpretativo de compreensão, com o conhecimento prévio ou o campo que os aprendizes precisam saber para acessar o texto". Os alunos leram as lendas na internet e escolheram aquelas que mais apreciaram para contar aos colegas. A partir do compartilhamento das estórias, a professora guiou a discussão sobre as características comuns à maioria dos textos expostos - oralidade, terror, baseadas em relatos e consideradas reais.

A noção de registro (MARTIN; ROSE, 2012) e as suas dimensões de funcionamento na língua foram abordadas e incluem campo (sobre qual assunto eram os textos), relação (os interlocutores envolvidos) e modo (falado ou escrito). Ao explorar o conhecimento prévio dos alunos sobre o gênero, foi possível traçar comparações a respeito das lendas que os alunos conheciam (modo falado) e os explorados em sala de aula (modo escrito, na internet).

Nas aulas seguintes, a professora realizou atividades que contemplaram a leitura detalhada, com os textos selecionados pelos alunos: os aspectos linguísticos dos textos, incluindo o léxico utilizado e o sentido global dos textos. A professora projetou a imagem do texto no quadro e distribuiu cópias com o texto para que eles pudessem marcá-lo com canetas coloridas. A professora lia as passagens e direcionava as perguntas a um aluno, para que ele pudesse contribuir e elaborar a sua própria resposta. 
No desenvolvimento da atividade de leitura detalhada ${ }^{6}$, o professor identificou as passagens que considera mais importantes para serem trabalhadas em sala de aula. O professor sinalizou quais aspectos do texto os alunos apresentariam dificuldade, caso nenhum suporte fosse destinado a eles no momento da leitura. No momento da aplicação, cada passagem escolhida relaciona-se com os excertos anteriores de forma que o sentido global do texto emergisse a partir das relações existentes em cada passagem. Após esta atividade, os alunos iniciaram discussões acerca do texto e, divididos em grupos, responderam oralmente questões propostas 7 .

A partir da atividade, discutiu-se em qual contexto sócio comunicativo o texto foi produzido. Primeiramente, explorou-se a autoria do texto, que era desconhecida; também se discutiu a incerteza da época em que foi escrita ou contada pela primeira vez e, por fim, quem são os interlocutores atuais (leitores do site) e em que meio ele está disponível (escrito ou falado). Desta forma, exploraram-se as noções de campo, relação e modo.

Após as leituras das lendas, iniciou-se o segundo momento de aplicação do Ciclo de Aprendizagem: com as notícias jornalísticas. A sequência desenvolvida compreendeu a preparação para a leitura e a leitura detalhada de duas notícias, reescrita conjunta, reescrita individual, construção conjunta e escrita autônoma, respectivamente. O primeiro texto lido pelos alunos foi a notícia intitulada "Médica morre após ser baleada durante assalto em Porto Alegre" (Quadro 2), veiculada nas mídias impressas e on line. A preparação para a leitura ou desconstrução do gênero foi estabelecida a partir d discussão sobre o texto, abordando-se em qual mídia foi veiculado. Os alunos perceberam prontamente que se tratava de uma notícia on line, pois identificaram os símbolos de compartilhamentos em redes sociais. Neste momento, discutiu-se qual é objetivo sócio comunicativo das notícias

\footnotetext{
${ }^{6} \mathrm{O}$ texto trabalhado na leitura detalhada, Os meninos verdes, foi selecionado pelos alunos e os critérios utilizados foram estabelecidos a partir do nível de dificuldade enfrentado no momento da leitura e no interesse dos alunos em explorar o texto. Texto disponível em http://ahduvido.com.br/50-lendas-urbanas, acesso em 23/04/2020.

7 As questões indicavam que após a leitura e as informações compartilhadas com os colegas e a professora, os alunos poderiam comentar com os colegas a respeito de: quem é atribuído a autoria do texto? Em que ano a estória teria sido escrita? Por que não existe certeza sobre a data da estória? O texto foi primeiramente falado ou escrito? Em que meio ele foi usado para ser veiculado na sociedade? Onde o texto foi veiculado atualmente? Quem são os potenciais leitores do texto?
} 
que, de acordo com a Martin e Rose seria a relatar eventos. Explorou-se, a partir disso, se todos os eventos se tornam notícias, quem escreve as notícias que os alunos leem (notícia sobre famosos, na sua maioria), como é o layout das notícias (foto, texto, logo de compartilhamento da rede social). A noção de núcleo (título ${ }^{\wedge}$ lead) foi compreendida pelos alunos, então explorou-se a noção de título e subtítulo, além das expansões de informações dadas a partir de um título cuja função seria a de chamar a atenção do leitor para acessar a notícia.

A análise do gênero segue o proposto pela Escola de Sidney e a estrutura de fases proposta por White (1998): o título e o lead da notícia, que constituem o seu núcleo. Os parágrafos são os satélites independentes que retomam e expandem as informações contidas no núcleo.

Quadro 2: Análise do gênero notícia

\begin{tabular}{|c|c|c|}
\hline & Etapas do gênero & Texto \\
\hline \multirow{7}{*}{ 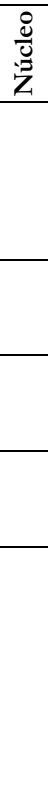 } & Título & Médica morre após ser baleada durante assalto em Porto Alegre \\
\hline & $\begin{array}{c}\text { Lead } \\
\text { Quem ^ o que }\end{array}$ & $\begin{array}{l}\text { Graziela Müller Lerias, } 32 \text { anos, estava parada no semáforo, acompa- } \\
\text { nhada da irmã mais nova, quando dois homens abordaram o veículo. }\end{array}$ \\
\hline & $\begin{array}{c}\text { Satélite } 1 \\
\text { Retoma o ocorrido em } \\
\text { detalhes } \\
\text { Quem } \wedge \text { o que }^{\wedge} \\
\text { quando }^{\wedge} \text { o que }{ }^{\wedge} \text { onde }\end{array}$ & $\begin{array}{l}\text { A médica Graziela Müller Lerias, } 32 \text { anos, morreu às } 4 \mathrm{~h} 40 \text { desta se- } \\
\text { gunda-feira (15) após ser baleada durante um assalto em Porto Alegre } \\
\text { neste domingo (14). Ela não resistiu aos ferimentos e morreu no Hos- } \\
\text { pital Cristo Redentor. }\end{array}$ \\
\hline & $\begin{array}{l}\text { Satélite } 2 \\
\text { Como }\end{array}$ & $\begin{array}{l}\text { Graziela estava parada no semáforo, acompanhada da irmã mais nova, } \\
\text { quando dois homens armados se aproximaram e tentaram abrir a porta } \\
\text { do veículo. Logo em seguida abriram fogo, atingindo a vítima. }\end{array}$ \\
\hline & $\begin{array}{c}\text { Satélite } 3 \\
\text { Como^ }{ }^{\wedge} \text { que }\end{array}$ & $\begin{array}{l}\text { As duas conseguiram descer do carro. Graziela foi levada em estado } \\
\text { gravíssimo para o Hospital Cristo Redentor, onde acabou morrendo. } \\
\text { Os bandidos conseguiram fugir com o veículo da médica. }\end{array}$ \\
\hline & $\begin{array}{c}\text { Satélite } 4 \\
\text { Descrição das ações } \\
\text { dos familiares e amigos. }\end{array}$ & $\begin{array}{l}\text { Ainda na noite de domingo, familiares de Graziela iniciaram uma cam- } \\
\text { panha nas redes sociais para pedir doações de sangue para a médica. No } \\
\text { entanto, a vítima, que passou por cirurgia, não resistiu. }\end{array}$ \\
\hline & $\begin{array}{l}\text { Satélite } 5 \\
\text { Confere voz à entidade } \\
\text { representativa de classe } \\
\text { a qual a médica per- } \\
\text { tence e expõe a situa- } \\
\text { ção de violência no es- } \\
\quad \text { tado. }\end{array}$ & $\begin{array}{l}\text { Após a confirmação da morte, o Sindicato Médico do Rio Grande do } \\
\text { Sul divulgou nota manifestando 'dor e revolta'. "O Sindicato Médico do } \\
\text { RS (SIMERS) manifesta dor e revolta diante da morte brutal da médica } \\
\text { Graziela Muller Lerias, } 32 \text { anos, vítima da violência que atinge níveis } \\
\text { insuportáveis no Estado, principalmente em Porto Alegre. A categoria } \\
\text { está em luto. A direção da entidade reforça que a perda da jovem reflete } \\
\text { um problema generalizado que afeta todos os gaúchos", diz o texto pu- } \\
\text { blicado. }\end{array}$ \\
\hline
\end{tabular}

Fonte: gaúchazh ${ }^{8}$.

${ }_{8}$ Disponível em https://gauchazh.clicrbs.com.br/seguranca/noticia/2016/08/medica-morre-apos-ser-baleadaem-assalto-na-zona-norte-de-porto-alegre-7271941.html (último acesso em 20/04/2020). 
A leitura detalhada realizada com o texto, ilustrado no Quadro 2, envolveu os seguintes passos: a identificação dos elementos presentes em notícias, a saber: quem, o que, quando, onde e como. Além desses elementos, os alunos, com canetas coloridas, marcaram os ângulos/pontos de vista de autoridades. Os alunos realizaram marcações em seus textos à procura desses traços textuais. Além de ser um gênero mais conhecido visual e culturalmente pelos alunos, o texto é mais acessível no que concerne a expressões que representem problemas para o entendimento global do texto.

Com o objetivo de analisar o texto, convencionaram-se cores para marcar a reportagem estabelecidas da seguinte maneira: amarelo: quem, vermelho: o que, azul: quando, rosa: onde, verde: como e marrom: versões oficiais e/ órgãos representativos de classes. A concepção de satélites foi desafiadora; a consciência textual necessária para entender a ideia de retomada de sentido ao longo do texto a partir das informações contidas no núcleo estava um pouco além do que os alunos conseguiriam compreender.

A leitura detalhada foi desenvolvida considerando a sequência de preparação, foco, identificação, afirmação e elaboração considerando as marcas textuais de cada satélite. No título, lead e nos satélites da notícia, por exemplo, exploraram-se formas que o texto apresenta sobre quem a notícia relata os acontecimentos (médica, Graziela Müller Lerias, a médica Graziela Müller Lerias, Graziela). A preparação consistiu na leitura da notícia; o foco salientou sobre quem é o relato do texto; a identificação deu-se pelo destaque com marcadores coloridos no texto e a elaboração ocorreu por meio de contribuições orais dos alunos. ${ }^{9}$

Em cada satélite, aspectos relevantes ao desenvolvimento do gênero foram destacados no momento da leitura detalhada, como o refinamento e a descrição do ocorrido (o que, como e onde aconteceu), as consequências (se alguém foi preso) e discursos dos

\footnotetext{
${ }^{9}$ Conforme estabelecido por Martin e Rose (2012), é importante expandir o vocabulário dos alunos. Dessa forma, as perguntas direcionadas aos alunos foram relativas à futura escrita deles, como: caso você fosse escrever uma notícia, qual profissão você atribuiria a esta pessoa? 
envolvidos (familiares, autoridades, órgãos representativos). Outras noções, como confiabilidade da notícia, também foram discutidas, principalmente aquelas circulantes nas redes sociais, em que o leitor não dispõe de mecanismos que indiquem se a notícia é ou não verdadeira.

A próxima estratégia prevista pelo Ciclo de Aprendizagem e proposta aos alunos foi a reescrita conjunta. Os alunos, coletivamente e com a supervisão da professora, reescreveram uma passagem da notícia trabalhada, usando o computador e o projetor de vídeo. $\mathrm{O}$ trecho escolhido compreendia o título, o lead e o primeiro satélite, pois apresentam todas as características relevantes de uma notícia. De acordo com Martin e Rose (2012), é preciso que os padrões discursivos sejam mantidos no momento da reescrita, embora se mantenha a necessidade de que as ideias sejam propostas pelos alunos, para que eles utilizem a sua imaginação. Os alunos propuseram temas variados das lendas urbanas, que foram projetadas em um quadro branco, de forma que todos os alunos pudessem opinar. A partir de uma chuva de ideias sobre as lendas urbanas, os alunos acordaram em escrever sobre o ataque da loira do banheiro em uma escola de Porto Alegre.

Para facilitar a identificação das fases do gênero, os alunos escreveram diretamente em um quadro, conforme descrito no Quadro 3.

Quadro 3: Reescrita conjunta

\begin{tabular}{|c|c|l|}
\cline { 2 - 4 } \multicolumn{1}{c|}{} & $\begin{array}{c}\text { Etapas do } \\
\text { gênero }\end{array}$ & \multicolumn{1}{c|}{ Texto } \\
\hline \multirow{2}{*}{\begin{tabular}{c} 
Lútulo \\
\cline { 2 - 4 }
\end{tabular}} & Lead & $\begin{array}{l}\text { Stefanny Santos, 12 anos, estava escondida no banheiro para não assistir aula. A } \\
\text { aluna estava com a colega, Luiza Antunes, 13 anos, que presenciou o ataque de uma } \\
\text { loira, ainda não identificada. }\end{array}$ \\
\hline Satélite 1 & $\begin{array}{l}\text { A estudante Stefanny Santos, 12 anos, morreu às 14h40 desta sexta-feira, 13 de no- } \\
\text { vembro, após ser atacada em sua escola, na zona Sul de Porto Alegre. Ela foi levada } \\
\text { ao Hospital da Restinga, mas não sobreviveu }\end{array}$ \\
\hline
\end{tabular}

Fonte: arquivo pesquisadora 
A atividade de reescrita conjunta foi uma tarefa que envolveu os alunos na escrita: enquanto um aluno revezava-se na digitação, os demais contribuíam com o desenvolvimento do texto. É neste momento que os alunos se utilizaram dos padrões discursivos levantados na leitura detalhada, como por exemplo, as variadas formas de referir-se à pessoa à qual se reporta a notícia ("aluna", "Stefanny", "estudante Stefanny"). A tarefa de reescrita conjunta foi desenvolvida conforme proposto por Butt et. al. (2003) e envolveu toda a turma na atividade de escrita, acompanhada de explorações e discussões acerca do contexto, do significado e das expressões contidas nos padrões textuais lidos.

A reescrita individual, próxima etapa implementada, foi o momento em que os alunos escreveram textos individualmente. Alguns alunos utilizaram-se das ideias lançadas na reescrita conjunta (lendas urbanas, personagens e cenários) como ponto de partida para a sua escrita, outros realizaram pesquisas no intuito de encontrar outras lendas para explorar outras ideias. Abaixo, segue a reescrita individual de uma aluna, baseada na lenda da brincadeira do copo.

Quadro 4: Reescrita individual

\begin{tabular}{|c|c|c|}
\cline { 2 - 3 } \multicolumn{1}{c|}{} & $\begin{array}{c}\text { Etapas do } \\
\text { gênero }\end{array}$ & Texto \\
\hline \multirow{2}{*}{\begin{tabular}{c} 
Título \\
\cline { 2 - 3 }
\end{tabular}} & Lead & $\begin{array}{l}\text { Menino morre depois de jogar a brincadeira do copo } \\
\text { brincadeira do copo com amigos. }\end{array}$ \\
\cline { 2 - 3 } & Satélite 1 & $\begin{array}{l}\text { Guilherme Francisco da Silva, de 18 anos, estudante de medicina, morre em aci- } \\
\text { dente de carro na AV. Pedro Gonçalves, dia 24 de novembro, às 9 horas. Os bom- } \\
\text { beiros chegaram no local às 10 horas e viram o corpo do Guilherme. }\end{array}$ \\
\hline
\end{tabular}

Fonte: arquivo pesquisadora

A reescrita individual seguiu a mesma proposta de reescrita conjunta, ou seja, de escrever textos que apresentassem o título, o lead e um satélite. O primeiro aspecto importante com relação à escrita foi que o aluno compreendeu a lenda urbana - brincadeira do copo - e apropriou-se das leituras para desenvolver a notícia. Além disso, percebeu-se 
que o estudante compreendeu gênero proposto ao reconhecer aspectos relevantes à escrita de notícias (quem, o que, quando, como e onde ocorreram os fatos).

Nas atividades de reescrita individuais e coletivas, os alunos utilizaram-se do texto lido para explorar as suas habilidades escritas, percorrendo o caminho da leitura para escrever textos que sigam os padrões do gênero abordado. Assim, é importante ressaltar a relevância da atividade no desenvolvimento da escrita, principalmente para aquelas cujo letramento está abaixo do ideal. Ainda que a atividade tenha sido relevante a todos os alunos, aqueles com maiores dificuldades também conseguiram realizar as atividades.

Neste sentido, foram consideradas as estratégias propostas por Butt et. al. (2003), com relação ao trabalho independente dos aprendizes em sala de aula. De acordo com os autores, é necessário que ocorra a monitoramento pelo professor e o apoio coletivo dos colegas em um projeto estruturado com estágios previamente estabelecidos pelo grupo. Outrossim, é determinante que se construa uma ligação entre as leituras e as consultas realizadas e as atividades requisitadas. Diante disso, as atividades de escrita realizadas coletivamente são uma importante etapa do trabalho em sala de aula, pois oferece o suporte necessário e prepara os estudantes para a construção independente.

Assim, o monitoramento sobre o qual os autores discorrem ocorreu de forma contínua ao da aplicação do Ciclo de Aprendizagem da Pedagogia de Gêneros, sendo adaptada às necessidades particulares do grupo, que demandou novamente uma abordagem dos macros elementos em nível semântico do texto, que são, conforme Butt et. al. (2003.), a textura de um texto, ou seja, "as cadeias” de significado que contribuem para a coesão; e a estrutura textual, "que compreende os padrões e os estágios ou fases que realizam determinada função nos textos completos” (BUTT et. al., 2003, p. 262, tradução nossa). Além disso, ressalta-se a necessidade de replanejamento ao longo do processo, que envolve avaliar o desenvolvimento e a implementação do Ciclo de Aprendizagem.

As produções coletivas, após escritas em papel e lidas pela professora, que sugeriu alterações, foram digitadas na plataforma google drive, de forma que a docente acompanhava a escrita no momento em que acontecia. Os textos caracterizaram-se por serem pouco 
extensos, mas foi possível observar a melhora da escrita desenvolvida, conforme discutido na seção subsequente.

\section{Análise da produção da construção e produção do texto escrito}

Ao longo do desenvolvimento da implementação do Ciclo de Aprendizagem, alguns aspectos da sua aplicação mostraram-se importantes no processo de letramento dos alunos envolvidos, como os conceitos de registro e de gênero segundo a Linguística Sistêmico Funcional. Sob a perspectiva da LSF, há um estrato mais externo às metafunções, o registro e está relacionado às três funções da língua: campo, relação e modo. O registro é, de acordo com Halliday e Hasan (1989, p. 41: tradução nossa), “o que você está falando no momento, dependendo do que você está fazendo e a natureza da atividade em que a língua está funcionando". Dessa forma, o registro é caracterizado simultaneamente em três dimensões: o que está sendo falado e qual é a situação envolvida (campo); quem está envolvido (relação) e se a interação é falada ou escrita (modo). O registro é, assim, abordado a partir das suas variáveis de campo, relação e modo; e como essas variáveis apresentam-se no texto no sentido de caracterizar o gênero notícia.

A classificação tipológica proposta pela Escola de Sidney conceitua o gênero notícia como pertencente à família das Estórias e apresenta como principal propósito social engajar os seus leitores. Especificamente, o gênero notícia evidencia como objetivo principal relatar eventos atuais, ou seja, eventos considerados importantes social e coletivamente. Assim, as notícias são construídas a partir de um título apelativo e deveriam iniciar em qualquer parte do acontecimento para ser mais apelativa e engajar os seus leitores intercalando "no tempo diferentes aspectos dos eventos" arrolados (MARTIN; ROSE, 2008, p. 72: tradução nossa).

Considera-se, então, que as variáveis de registro (campo, relação e modo) são instanciadas pelas estruturas léxico-gramaticais da língua para realizar o gênero notícia. Assim, as variáveis contextuais funcionam no texto e apresentam-se de forma a caracterizar o gênero desenvolvido. Da mesma forma, procura-se entender como o gênero notícia, cujas 
etapas são caracterizadas por satélites que retomam e expandem as informações apresentadas no núcleo do texto - o título e o lead - são desenvolvidas pelos alunos em suas produções escritas. Nesse sentido, busca-se compreender como as escolhas dos alunos são importantes no momento de escrita e em que medida elas são determinadas pelas leituras realizadas ao longo da ocorrência do projeto de letramento proposto. Assim, a seguinte notícia, produzida por um aluno do sexto ano do Ensino Fundamental, foi selecionada para ser analisada a partir dos estratos do gênero e do registro.

Quadro 6: Notícia 1 - escrita autônoma

\begin{tabular}{|c|c|}
\hline Título & \multicolumn{1}{c|}{ Título Palhaço ataca novamente no Parque Aquático } \\
\hline Lead & \multicolumn{1}{c|}{$\begin{array}{c}\text { Homem vestido de palhaço rapta criança } \\
\text { e mata ela em Parque Aquático de Porto Alegre. }\end{array}$} \\
\hline Satélite 1 & $\begin{array}{l}\text { Cláudia Pereira, de 10 anos, foi em um passeio da escola no Parque Aquático. Cláudia estava em } \\
\text { uma das piscinas do Parque quando um homem, vestido de palhaço a chamou para pedir uma } \\
\text { informação. Minutos depois, colegas escutam gritos e a professora, achou Cláudia atrás do ba- } \\
\text { nheiro morta, com o peito aberto. }\end{array}$ \\
\hline Satélite 2 & $\begin{array}{l}\text { A tragédia aconteceu dia 13 de abril em uma tarde de quinta-feira. Os colegas e professores } \\
\text { ficaram chocados com o acontecimento. }\end{array}$ \\
\hline Satélite 3 & $\begin{array}{l}\text { De acordo com as testemunhas, os visitantes do Parque Aquático disseram que o palhaço era } \\
\text { um homem que trabalhava em um circo que não existe mais. Ele tinha muitas passagens pela } \\
\text { polícia, todas eram de roubo de órgãos. Ele matava a vítima e tirava os órgãos para vender. } \\
\text { Polícias resolveram não revelar o nome do homem vestido de palhaço. }\end{array}$ \\
\hline Satélite 4 & $\begin{array}{l}\text { O homem vestido de palhaço foi preso em sua casa, 3 dias depois de matar a vítima Cláudia } \\
\text { Pereira. Vizinhos afirmam que o palhaço chegou em sua casa com um caminhão com isopores, } \\
\text { quando os policiais abriram os isopores só havia órgãos. }\end{array}$ \\
\hline Satélite 5 & $\begin{array}{l}\text { O advogado do palhaço, afirmou que ele matava as pessoas e tirava os órgãos por não saber o } \\
\text { que estava fazendo. Ele alegou que seu cliente é desequilibrado emocionalmente. }\end{array}$ \\
\hline
\end{tabular}

Fonte: arquivo pesquisadora.

A notícia 1, produzida por um aluno durante a etapa de escrita autônoma, foi considerada boa em termos de resultado da implementação do Ciclo de Aprendizagem. É possível afirmar que o texto desenvolvido responde à proposta estabelecida, pois é uma notícia escrita a partir das leituras realizadas sobre ataques de palhaços, durante as etapas de busca de informações, de desconstrução e de leitura detalhada das lendas, de acordo com o Ciclo de Aprendizagem e a sua implementação.

Com relação aos estágios do gênero, a notícia 1 apresenta a estrutura de título, lead e cinco satélites bem desenvolvidos ao longo da escrita. O título evidencia uma informação 
“palhaço ataca novamente no Parque Aquático". A informação mais relevante, no entanto, é explicitada no lead "bomem vestido de palhaso rapta criança e mata ela em Parque Aquático em Porto Alegre". Finalmente, os satélites retomam e ampliam as informações contidas no núcleo, apesar da inconsistência presente no título (não há explicação, no texto, de quando houve outro ataque, evidenciado pelo uso de "novamente"). De fato, o propósito era colocar que o palhaço havia atacado anteriormente, como pode ser constatado no decorrer do texto, nos trechos "Ele tinha muitas passagens pela polícia, todas eram de roubo de órgãos" e "o palhaço chegou em sua casa com um caminhão com isopores", respectivamente. ${ }^{10}$

No primeiro satélite, são discorridos como e onde o fato ocorreu, além de ampliar quem é a criança, "Cláudia Pereira, 10 anos". Além disso, são fornecidas as principais informações de como a sequência de fatos ocorreram, de acordo com a descrição de lugar "em um passeio da escola no Parque Aquático", e como aconteceu o fato, "quando um homem, vestido de palhaço a chamou para pedir uma informação". A aluna utiliza alguns recursos para levar ao clímax do enredo, como se pode verificar na sentença "Minutos depois, colegas escutam gritos", para finalizar com o fato mais relevante da notícia: "Cláudia [está] no banbeiro morta, com o peito aberto".

O satélite 2 adiciona a informação exata de quando aconteceu o fato, no trecho "aconteceu dia 13 de abril em uma tarde de quinta-feira", além de trazer o ponto de vista dos colegas e professores, que estão "chocados com os acontecimentos". Da mesma forma, no satélite 3, a aluna agrega mais detalhes, ao colocar que o palhaço "tinha muitas passagens pela polícia" e de que ele "tirava os órgãos [das vítimas] para vender". No satélite 4, igualmente, a aluna adiciona quando o palhaço foi preso e que possuía isopores em sua casa que "só havia órgãos". Por fim, no satélite 5, a nova informação apresentada é de que, de acordo com o advogado, o palhaço "é desequilibrado emocionalmente". Assim, a aluna explora os recursos contextuais, semânticos e léxico-gramaticais disponíveis em sua escrita, ao utilizar, em cada satélite, um dado novo relacionado ao ocorrido.

10 Outra possível explicação para o ponto de vista desenvolvido pela aluna está relacionada às leituras realizadas: como já havia relatos de outros ataques de palhaços, houve novamente outro, neste caso, em um parque aquático. 
A sequência em cada satélite apresenta algumas características de narrativa, principalmente relacionadas ao tempo cronológico desenvolvido no texto, como no primeiro satélite, ao utilizar a expressão "Minutos depois", embora não predomine ao longo da escrita. Os ângulos da notícia foram bem explorados pela aluna, que abordou as circunstâncias de ângulo no desenvolvimento dos satélites: "Os colegas e professores ficaram chocados com o acontecimento", "De acordo com as testemunhas", "Vizinhos afirmam" e "O advogado do palbaço afirmou". Assim, ao explorar os pontos de vista sobre o ocorrido, a aluna estabelece, em sua escrita, a confiabilidade da notícia, pois confere voz aos envolvidos nos fatos. Além disso, é possível afirmar que a escrita engaja o leitor a lê-la até o final, pois a aluna acrescenta elementos que envolvem percepção de quem lê; assim, ao expandir e agregar novos elementos em cada satélite, estimula o leitor a querer finalizar a leitura do texto.

No que diz respeito ao registro da notícia 1 , seus aspectos são bem desenvolvidos ao longo da notícia. Em primeiro lugar, a variável contextual campo é bem realizada, visto que a aluna se apropria da lenda urbana envolvendo ataques de palhaços, retextualizandoa em sua escrita, bem como demonstra ter se apropriado das leituras e pesquisas realizadas, ao trazer vocabulário adequado no desenvolvimento da escrita da notícia.

O modo, apesar de apresentar algumas marcas de oralidade ao longo do texto como em mata ela", "foi em um passeio" e "ele tinha muitas passagens pela polícia", apresenta-se apropriado à escrita. Percebe-se, da mesma forma, uma tentativa autoral da aluna na utilização de expressões utilizadas no modo escrito, principalmente relacionado às escolhas dos processos verbais - "revelar", "afirmam/afirmou" e alegou".

Por fim, a variável contextual relação foi bem desenvolvida e engaja o leitor em sua leitura ao relatar de forma adequada os fatos ocorridos, ao agregar informações significantes no desenvolvimento dos fatos - como tráfico de órgãos, passagens anteriores pela polícia. Além disso, há uma tentativa de estabelecer os ocorridos como verdadeiros, ao trazer o ponto de vista das testemunhas, dos vizinhos e do advogado do palhaço. Há uma distância média entre a aluna e os seus potenciais leitores, que é a comunidade da escola.

A análise é resumida no Quadro 7. 
Quadro 7: detalhamento da notícia 1

\begin{tabular}{|c|c|c|c|}
\hline Estratos & \multicolumn{2}{|c|}{ Realização } & Desenvolvimento \\
\hline \multirow{7}{*}{$\begin{array}{l}\text { Contexto } \\
\text { de } \\
\text { Cultura }\end{array}$} & \multirow{7}{*}{ Gênero } & Título & Introdução da informação \\
\hline & & Lead & Informação mais relevante \\
\hline & & Satélite 1 & Especifica como, onde e quem são os envolvidos \\
\hline & & Satélite 2 & $\begin{array}{l}\text { Quando ocorreu o fato e traz o ponto de vista de colegas e pro- } \\
\text { fessores }\end{array}$ \\
\hline & & Satélite 3 & Amplia as informações sobre o palhaço \\
\hline & & Satélite 4 & $\begin{array}{l}\text { Informa quando o palhaço foi preso e fornece novo dado sobre } \\
\text { ele (tráfico de órgãos) }\end{array}$ \\
\hline & & Satélite 5 & Traz o ponto de vista do advogado do palhaço \\
\hline \multirow{3}{*}{$\begin{array}{l}\text { Contexto } \\
\text { de Situa- } \\
\text { ção }\end{array}$} & \multirow[b]{3}{*}{ Registro } & Campo & $\begin{array}{l}\text { Notícia a partir da retextualização da lenda urbana sobre a te- } \\
\text { mática de ataques de palhaços }\end{array}$ \\
\hline & & Modo & $\begin{array}{l}\text { Modo escrito com algumas marcas de oralidade e predominân- } \\
\text { cia da estrutura informativa. }\end{array}$ \\
\hline & & Relação & $\begin{array}{l}\text { Escritor e potenciais leitores do texto, com distância média en- } \\
\text { tre os envolvidos. Investimento autoral em uma tentativa de en- } \\
\text { gajar os leitores na progressão de informações. Tentativa de es- } \\
\text { tabelecer os fatos como verdadeiros, ao conferir voz a várias } \\
\text { pessoas. }\end{array}$ \\
\hline
\end{tabular}

Fonte: autoria da pesquisadora

Ao analisar uma das notícias produzidas pelos alunos ao longo do processo de implementação da Pedagogia de Gêneros, levantam-se algumas hipóteses com relação às etapas de implementação do Ciclo de Aprendizagem. Primeiramente, em se tratando do contexto situacional, e as suas variáveis de campo, relação e modo, pode-se afirmar que o aluno progrediu no tocante à compreensão dos aspectos trabalhados ao longo das etapas do Ciclo de Aprendizagem. Assim, os aprendizes desenvolveram o campo a partir das leituras, das buscas e das discussões acerca das lendas urbanas para retextualização em notícias. A temática sobre lendas urbanas era parcialmente conhecida aos alunos, e as atividades de exploração expandiram o seu conhecimento. Assim, as discussões possibilitaram a sua consolidação, pois foi a partir das trocas de informação que os estudantes ampliavam o repertório ainda não conhecido. Da mesma maneira, as atividades de leitura detalhada mobilizaram aspectos dos textos de forma a ampliar o modo escrito das notícias produzidas. Os alunos, então, familiarizavam-se com o modo escrito dos textos, e utilizaram os recursos linguísticos que caracterizam a escrita como um todo. Assim, ao longo das atividades que envolviam a leitura das notícias, a saber, a preparação para a leitura e a leitura detalhada, os alunos construíam significados que poderiam ser acessados por eles no momento da sua 
escrita. Da mesma forma, as atividades de reescrita conjunta e individual propiciaram momentos em que os alunos poderiam mobilizar a língua de forma a caracterizá-la em seu modo escrito.

A variável contextual relação fora bem desenvolvida pelos alunos em seus textos, visto que os alunos investiram na autoria de seus textos, colocando-se na posição de autorescritor de suas notícias. Ao estabelecer a relação entre os leitores-receptores das notícias que seriam lidas por pessoas da comunidade escolar que, muitas vezes, desconheciam as lendas urbanas, os alunos projetavam-se como autores de notícias cujo enredo era de seu conhecimento e que partilhariam com os potenciais leitores.

\section{Considerações finais}

A importância do desenvolvimento das atividades previstas pela Pedagogia de Gêneros em sala de aula reside no fato de que, ao criar um contexto de exploração e de uso da língua, os alunos e professores estabelecem um ambiente colaborativo de trabalho que se alterna em estratégias guiadas de produção. Ao alternar as estratégias empregadas, de atividades coletivas e individuais, cria-se um ambiente colaborativo de trabalho que envolve os estudantes na tarefa de ler e escrever textos que envolve o conhecimento cultural, ou seja, sobre o objetivo do texto (gênero), do assunto (campo), a função e a relação estabelecida por quem escreve (relação) e a forma de comunicação envolvida e como acessá-la (modo).

A Pedagogia de Gêneros, ao estabelecer o Ciclo de Aprendizagem com níveis de suporte para o ensino e aprendizagem de leitura e de escrita, estimula o engajamento entre os alunos e entre os alunos e o professor, visto que estabelece atividades coletivas, com maior suporte, e atividades individuais, com menos assistência. Em termos práticos, os alunos passam por um processo progressivo de produção de significados, seja a partir da leitura, seja a partir da escrita e, ao acessar níveis variados de compreensão de significados - literais, inferenciais e interpretativos - os aprendizes começam a estabelecer relações produtivas entre o seu conhecimento de mundo e os textos lidos/produzidos. 
O desenvolvimento do Ciclo de Aprendizagem em um projeto de letramento em uma escola pública e os resultados apontados neste artigo mostram alguns caminhos possíveis de aplicação da Pedagogia de Gêneros. O atendimento de estudantes no turno inverso ao atendimento regular, além de uma demanda social e política, apresenta-se como uma oportunidade de planejamento de novas metodologias, ainda pouco exploradas. A aplicação do Ciclo de Aprendizagem mostrou-se uma alternativa interessante, visto que explora temáticas muitas vezes conhecidas dos alunos, mas estes ainda apresentam níveis de leitura e de escrita em desenvolvimento. O ensino explícito de gêneros, dessa forma, auxilia os alunos no processo de leitura e de escrita, visto que prepara os alunos de forma coletiva para a sua escrita individual. Ao reconhecer as suas etapas e fases e dominar o registro, o aluno consegue ler e escrever de forma mais autônoma e alcança níveis mais altos de letramento escolar. Ao pautar a abordagem textual do texto em contexto, a leitura e a escrita deixam de ser uma incógnita a ser resolvida e o aluno consegue traçar caminhos possíveis para desenvolvê-las de forma autônoma, a cada aplicação do Ciclo.

Por fim, espera-se que a Pedagogia de Gêneros seja mais uma ferramenta disponível aos professores de língua portuguesa para que seja possível formarmos cidadãos mais bem preparados social e culturalmente ao serem capazes de ler e se posicionar mais criticamente frente aos textos circulantes em nossa sociedade.

\title{
LEARNING CYCLE AND THE PRODUCTION OF JOURNALISTIC NEWS IN A SCHOOL CONTEXT
}

\begin{abstract}
This article is theoretically based on Halliday's Systemic-Functional Linguistics (2014) and on Gender Pedagogy (Martin; Rose, 2008, 2012) and aims to present the implementation of the Learning Cycle with students of the sixth year of Elementary School in a public school. It sought to thus present possible forms of explicit learning of the news genre, as well as autonomous writing texts. The methodology used is established by the Learning Cycle with students in the opposite shift to a literacy project, offered by a teacher in the municipal of the city. The analysis of a student's production is presented and the influence of the implementation of the Cycle on the literacy of the students involved is discussed.
\end{abstract}

PALAVRAS-CHAVE: Genre; Genre Pedagogy; Learning Cycle; Systemic-Functional Linguistics. REFERÊNCIAS 
Ah duvido - O que são lendas urbanas. Disponível em: http://ahduvido.com.br/50-lendasurbanas. Acesso em: 11 abr 2016

BRASIL. Ministério da Educação/Diretoria de Avaliação da Educação Básica (DAEB). Brasil no PIS A 2015. Sumário Executivo, Brasília, DF, 2016

BERNSTEIN, B. The structuring of pedagogic discourse. Routledge, 1990.

BERNSTEIN, B. Pedagogy, symbolic control, and identity: Theory, research, critique. Rowman \& Littlefield, 2000.

BUTT, D.; FAHEY, R.; SPINKS, S. \& ALLOP, C. Using Functional. Grammar: An Explorer's Guide. NationaL. Centre for English Language Teaching and Research, Sidney: Claredon Printing, 2003.

EGGINS, S. Introduction to systemic functional linguistics. New York/London: Continuum. 2014.

GOUVEIA, C. A. M. Compreensão leitora como base instrumental do ensino da producão escrita. In: SILVA, W. R.; SANTOS, J. S.; MELO, M. A. (org.), Pesquisas em Língua(gem) e demandas do ensino básico. Campinas, Pontes Editores, p. 203-231, 2014

HALLIDAY, M. A. K. An introduction to functional grammar. 5a ed. Revisada por MATTHIESSEN, C. M. I. M. London: Edward Arnold, 2014.

HALLIDAY, M. A. K.; An introduction to functional grammar. $2^{\text {a }}$ ed. London E. Arnold, 1994.

HALLIDAY, M. A. K. Language as social semiotics. 1978.

HALLIDAY, M. A. K.; HASAN, R. Language, context, and text: Aspects of language in a socialsemiotic perspective. 1989.

MARTIN, J. R. Grammar meets genre: Reflections on the "Sydney School". Arts: the journal of the Sydney University Arts Association, 22, 47-95, 2000.

MARTIN, J. R.; ROSE, D. Learning to write, reading to learn: Genre, knowledge and pedagogy in the Sydney School. Equinox, 2012.

MARTIN, J. R.; ROSE, D. Genre relations: Mapping culture. Equinox, 2008

PAINTER, C. Into the Mother Tongue: a case study of early language development, London, 1984.

ROSE, D. Genre, knowledge and pedagogy in the 'Sydney School' David Rose Artemeva, N \& A Freedman (Eds.) 2015 Trends and traditions in genre studies. Alberta, Canada: Inkshed, 2015a.

ROSE, D. New developments in genre-based literacy pedagogy David Rose In C A. MacArthur,S Graham, J Fitzgerald [Eds.] 2015 Handbook of Writing Research, 2nd Edition. New York: Guilford, 2015c 
ROSE, D. Analysing pedagogic discourse: an approach from genre and register. Functional Linguistics, 2014. Disponível em https://www.readingtolearn.com.au/wpcontent/uploads/2016/01/Analysing-pedagogic-iscourse.pdf>. Disponível em 21 abr 2020.

ROTHERY, J. Making changes: developing an educational linguistics. Hasan \& Williams. 1996, p. 86-123.

WHITE P. R. R. Telling Media Tales: The News Story as Rhetoric. Unpublished PhD thesis, University of Sydney. 1998.

Recebido em: 24/04/2020.

Aprovado em: 22/05/2020. 